\title{
ESPAÇOS INVISÍVEIS: ARTE E ARQUITETURA NA CIDADE CONTEMPORÂNEA
}

\section{INVISIBLE SPACES: ART AND ARCHITECTURE IN THE CONTEMPORARY CITY}

\author{
Julia Junqueira Ribeiro Pinto ${ }^{1}$
}

Resumo: Arte e arquitetura partilham questões comuns dentro do campo ampliado da cultura, visando a compreensão do mundo contemporâneo, no qual a cidade genérica, regida por produções imateriais de valor, é expoente. Parte necessária à manutenção deste sistema são os espaços residuais, por exemplo aqueles comumente gerados em renovações urbanas especulativas. É tamanha a dificuldade de se lidar com eles, são espaços ignorados, quase invisíveis. Porém, nesses lugares onde o tecido da cidade afrouxa - a densidade diminui, assim como os fluxos -, ficam evidentes os valores, dinâmicas e fraquezas contemporâneas. Daí a potência de intervenções que chamam a atenção para esses locais. Assim, o presente trabalho analisa e compara práticas recentes no contexto brasileiro de três artistas-arquitetos - Lotes Vagos, de Louise Ganz; Vazadores e Calçada, de Rubens Mano; e Amnésias Topográficas I, Amnésias Topográficas II e Espaços Públicos Invisíveis, de Carlos Teixeira para entender como eles lidam com a realidade espacial desse mundo capitalizado e fragmentado e ao mesmo tempo dinâmico e virtualizado. Palavras Chaves: arte e arquitetura, intervenção urbana, cidade contemporânea.

Abstract: Art and architecture share common issues within the expanded field of culture to understand the contemporary world, in which the generic city governed by immaterial production value, is exponent. Necessary part of the maintenance of this system are the residual spaces, for example those commonly generated in speculative urban renewal. It

\footnotetext{
${ }^{1}$ Graduanda em Arquitetura e Urbanismo pela Escola da Cidade - Faculdade de Arquitetura e Urbanismo/São Paulo. Orientada por Fernanda Mendonça Pitta.
} 
is such difficult to deal with these residues, so they are ignored, almost invisible. However, in those places where the fabric of the city loosens where density and flow decrease -, the contemporary values, dynamic and weaknesses are evident. Hence the power of interventions that draw attention to these sites. Therefore, this work analyzes and compares recent practices of three artists-architects in the Brazilian context Lotes Vagos by Louise Ganz; Vazadores and Calçada by Rubens Mano; and Amnésias Topográficas I, Amnésias Topográficas II and Espaços Públicos Invisíveis by Carlos Teixeira - to understand how they deal with the spatial reality of a capitalized and fragmented while dynamic and virtualized world.

Key words: art and architecture, urban intervention, contemporary city.

Arte e arquitetura partilham cada vez mais questões comuns dentro do que se pode entender como "campo ampliado" da cultura, dissolvendo antigas fronteiras disciplinares para a compreensão do mundo contemporâneo, no qual a cidade genérica, financeirizada e com vocação global é expoente (WISNIK, 2012: 167). Nela predominam produções imateriais de valor que regem a valorização econômica e o consumo permanente da imagem dessas cidades. Parte natural e necessária à manutenção deste sistema são os espaços residuais, fisicamente evidentes em renovações urbanas a partir de ações especulativas, barreiras entre público e privado, ou entre diferentes classes sociais.

Apesar de muitos terem consciência de sua existência, esses resíduos passam muitas vezes por despercebidos, invisíveis. Tamanha dificuldade de se lidar com eles, esses espaços são ignorados ou subutilizados. Porém, nesses lugares onde o tecido da cidade afrouxa, ou seja, onde ele é mais flexível e maleável, evidenciam-se noções de tempo, 
ritmo e regra diferentes da maior parte da cidade. Neles, os valores, dinâmicas e fraquezas dos espaços contemporâneos vêm à tona. Daí a potência de intervenções artísticas e arquitetônicas que chamam a atenção para esses locais, abordando questões como espacialidade, efemeridade, participação e evento buscando tensionar o público e o privado e assim quebrar com cotidiano programado.

Desta forma, o presente trabalho analisa e compara, por meio de referências teóricas, artigos críticos e entrevistas, práticas recentes no contexto brasileiro de três artistas-arquitetos - Lotes Vagos, de Louise Ganz; Vazadores e Calçada, de Rubens Mano; e Amnésias Topográficas I, Amnésias Topográficas II e Espaços Públicos Invisíveis, de Carlos Teixeira.

Rubens Mano, Louise Ganz e Carlos Teixeira são alguns dos agentes dessas intervenções em espaços residuais da cidade que de algum modo partem de uma formação em arquitetura para a realização de seus trabalhos. Mano, nascido em 1960 em São Paulo e formado em 1984 pela Faculdade de Arquitetura e Urbanismo de Santos, logo frequentou cursos de extensão em fotografia e se interessou pela paisagem urbana, e pelas correspondências entre imagem e espaço, desenvolvendo um trabalho dentro das artes visuais. Desde sua graduação, Mano optou pela linguagem artística para lidar com questões do espaço e da sociabilidade urbanas. Suas obras discutem a possibilidade de uma arquitetura efêmera que se relacione rapidamente com a paisagem (MANO, 2014: 1).

Teixeira formou-se em arquitetura pela Universidade Federal de Minas Gerais em 1992 e concluiu seu mestrado em Urbanismo pela 
Architectural Association de Londres em 1994. É autor dos livros Em Obras: História do Vazio em Belo Horizonte (Cosac Naify, 1999), O Condomínio Absoluto (C/Arte, 2009), Entre (Instituto Cidades Criativas, 2010) e um dos organizadores de Espaços Colaterais (Instituto Cidades Criativas, 2008). Com grande interesse em vazios urbanos, fundou o escritório Vazio S/A Arquitetura e Urbanismo em 2002, que segue ativo. Teixeira, por sua vez, não se vê como artista, acredita que tudo que faz gira em torno da arquitetura, de modo diferente de um estritamente pragmático (TEIXEIRA, 2014: 1).

Ganz, formou-se em arquitetura pela Universidade Federal de Minas Gerais em 1991 e em Artes Plásticas pela Universidade do Estado de Minas Gerais no mesmo ano. Concluiu seu mestrado em Ciências Sociais Aplicadas e Linguística, Letras e Artes pela Escola de Belas Artes da Universidade Federal de Minas Gerais em 2008, e seu doutorado em Linguística, Letras e Artes na Escola de Belas Artes da Universidade Federal do Rio de Janeiro em 2014. Desde 2002 trabalha com intervenções coletivas no espaço urbano que relacionam arte, paisagem e arquitetura, repensando os modos de ocupação e os usos do território, assim como o público e o privado. Até 2009 atuou com o também arquiteto e artista Breno Silva no escritório Ambulante, e depois disso juntouse com a artista Ines Linke para uma parceria, fundando o This Land Your Land. Atualmente, atua como artista e leciona Artes Plásticas na Universidade do Estado de Minas Gerais, em Belo Horizonte. Dessa maneira, com formação em ambos os campos - arquitetura e arte -, 
Ganz crê que não há mais uma dicotomia entre eles, são movimentos misturados (GANZ, 2014: 16).

Apesar de opiniões díspares e de trajetórias profissionais distintas, os trabalhos selecionados para análise produzidos por esses três indivíduos aproximam-se na medida em que tomam a cidade como campo de experimentação e propõem a ela novas possibilidades de existência, promovendo discussões que permeiam arte, arquitetura, urbanismo, política e cultura, uma vez que, segundo Nelson Brissac, "toda intervenção na cidade é necessariamente plural” (PEIXOTO, 2002: 12)

O trabalho Lotes Vagos foi uma série de 16 intervenções experimentais realizadas durante 2005, 2006 e 2008, entre as cidades de Belo Horizonte, Sabará e Fortaleza. Idealizado por Louise Ganz, contando com a posterior colaboração de Breno Silva, propunha ocupar e transformar lotes privados em espaços públicos durante um período, por meio do empréstimo pelos seus proprietários e do uso pela população. Nessa ação, a artista procurava realçar e subverter os territórios vazios que pontuam a cidade, comumente percebidos como áreas desocupadas ou marginais, compreendendo-os como uma rede potencial de invenção capaz de gerar oportunidades de convivência, ocupação e configuração do espaço urbano (GANZ e SILVA, 2009: 7). $100 \mathrm{~m}^{2}$ de grama (Belo Horizonte, 2005. Atividades diversas realizadas em um lote vago durante três meses, impulsionadas pelo plantio de $100 \mathrm{~m}^{2}$ de grama), a primeira intervenção da série Lotes Vagos, foi realizada na zona sul de Belo Horizonte durante três meses de 2005, em um lote de $500 \mathrm{~m}^{2}$ que possuía uma estrutura de obra em ruínas. A intervenção consistia no plantio 
de $100 \mathrm{~m}^{2}$ de grama com o auxílio dos moradores da região, ação que despertou demonstrações de interesse e manifestações afetivas, revelando desejos e catalisando outras atividades (GANZ e SILVA, 2009: 67).

A obra não foi concebida para ser visitada, mas vivida e construída. Aquele que antes era espectador passou a ser sujeito integrante, ativador, uma vez que o trabalho não foi oferecido como algo pronto, mas que envolvia a participação do público. Construídos pela própria população local numa micro escala de transformação do espaço habitado, as intervenções (plantio de horta, banquetes, etc) problematizavam os modos de vida sociais atuais abordando questões de propriedade, ambiente e comunidade numa esfera distinta da especulação e homogeneização. Dessa maneira, a obra ia além de um manifesto de resistência. Segundo a artista, foi uma experimentação propositiva que de fato promoveu uma intervenção no cotidiano, impulsionando a participação do cidadão na construção da cidade na escala da vizinhança, por meio de sua atividade dentro da obra (GANZ, 2008). Assim, o espaço pode ser entendido aqui como "lugar praticado", expressão de Michel Certeau que se refere a uma espacialidade temporizada, antropológica, histórica e corporal, como analisa Vera Pallamin (CERTEAU, 1984: 110 apud PALLAMIN, 2000: 39), enquanto que arte e arquitetura podem ser percebidas como possibilidade de movimento, uma vez neste espaço relacional, instável e tenso (WISNIK, 2012: 42).

Rubens Mano também realiza trabalhos com forte caráter político provocativo, introduzidos no espaço público de maneira muitas vezes sutil, como inserções "silenciosas" que não procuram provocar a des- 
continuidade do espaço, mas sugerir outros fluxos existentes no ambiente urbano por meio de um processo de ressignificação. Sua obra Vazadores (São Paulo, 2002. Instalação site specific de estrutura metálica e vidro que criava uma passagem na fachada da Bienal, controlada por câmera, gravador e monitor de vídeo, e um segurança), elaborada para a $25^{\mathrm{a}}$ Bienal Internacional de Arte de São Paulo, foi pensada a partir da experiência espacial de Mano. Dessa maneira, Vazadores refletiu uma incongruência entre o tema proposto pela Bienal naquele ano - a metrópole - e a implantação da mostra num espaço fechado para a cidade - o Pavilhão Ceccillo Matarazzo - e para discussões plurais sobre o assunto. A intervenção permitiu questionar o quanto a proposta da Bienal não se alinhava à maneira como a instituição gerenciava o seu espaço, já que mantinha controlado o acesso ao edifício do evento por meio de cobrança e de vigilância. (MANO, 2014: 4, 5). Como colocou Thais Rivitti, “o espaço do museu não era uma possibilidade, mas sim um ponto de partida" (RIVITTI, 2010: 156) para o questionamento das relações entre a instituição e a cidade propostas por Mano.

Com a intervenção Vazadores, o artista propunha inicialmente dois atravessamentos: um simbólico, que acabou não realizado, e outro físico. O primeiro seria um corte de 2,5m x $5 \mathrm{~m}$ em umas das lajes do edifício de modo a conectar visualmente o segundo andar com o térreo, que acabou não sendo realizado. Ele seria arrematado com uma cinta metálica e coberto com grade alveolar de aço carbono, igual às encontradas nos respiros do metrô. Dessa maneira, o trabalho procurava a debater questões de patrimônio histórico e espaço expositivo, podendo 
ser entendido como um descanso, uma oscilação no caminhar do visitante (MANO, 2013).

O trabalho realizado - o atravessamento físico -, por sua vez, constituía-se de uma estrutura discreta e sem indicação, que mimetizava e interceptava a fachada principal do edifício, oposta à entrada do evento naquele ano, de modo a formar um pequeno corredor com duas portas basculantes sem fechaduras, permitindo a livre e gratuita passagem de qualquer um. Como aponta Mano, o trabalho não era finalizado em sua fisicalidade, logo, as experiências que poderiam ser proporcionadas ali pela construção eram essenciais à sua natureza (MANO, 2014: 7). Nessa operação, o artista tencionava o debate sobre cidade, inclusão e as diversas instâncias que determinam ocupação e uso do espaço urbano, assim como problematizava estruturas espaciais e mentais da sociedade, buscando um "real enfrentamento entre a cidade e suas representações" (MANO, 2003: 63).

Entretanto, a obra rapidamente despertou reações. Logo após a abertura do evento, a direção da Bienal começou a "regrar" a passagem, que a princípio não tinha nenhum impedimento e permitia a entrada das pessoas sem o pagamento de ingresso. Alegando questões de segurança, a Bienal propôs um vigia para o trabalho, que não regularia, mas acompanharia o fluxo nessa passagem. Mano aceitou essa quase imposição com a condição de que essa figura ficaria dentro do edifício, a certa distância da obra. Diante dessa situação, o artista desenvolveu um monitoramento do controle que a Bienal faria sobre seu trabalho, instalando, 
assim, um monitor e um gravador de fita VHS supervisionados por outro segurança.

Por fim, a passagem estava muito restrita: com esse controle, a instituição acabava por obstruir a entrada, restringindo horários e o fluxo de visitantes. Essa postura contrariava a intenção do artista. Enxergando nela uma "morte anunciada" do trabalho, Mano solicitou fechar e desmontar a obra antes do fim da mostra. A reação da direção da Bienal à transgressão espacial e institucional de Mano parecia demonstrar a pouca habilidade da instituição em lidar com a desarticulação de sua lógica institucional.

A obra, portanto, expandiu-se e revelou distorções sobre as expectativas e responsabilidades geralmente associadas à instituição cultural (BATISTA e MANO, 2002: 73). Dessa maneira, a obra colocava em discussão o posicionamento da Fundação Bienal de São Paulo em relação ao próprio tema proposto, assim como sua relação com o espaço público do Parque Ibirapuera e da cidade ao redor. Além disso, lidava com limites e bordas do que é fechado e aberto, do que é público, semipúblico e privado, e ainda com convenções e padrões comportamentais e com a percepção espacial das pessoas e suas reações - ou não reações - à elementos silenciosos, disfarçados, camuflados, e possivelmente invisíveis ou surpreendentes na paisagem urbana.

A experiência com a visibilidade e a invisibilidade do espaço urbano já havia sido discutida por Rubens Mano no trabalho Calçada (São Paulo, 1999. Instalação site specific que estendia a tubulação elétrica da Oficina Cultural Oswald até a calçada, disponibilizando energia elétrica 
24h gratuitamente), realizado na Oficina Cultural Oswald de Andrade, no Bom Retiro. Analisando aquele espaço, Mano observou a pouca conexão entre o "espaço público aberto", da rua, e o "espaço público fechado", do centro cultural (MANO, 2014: 2). A rua mostrava-se muito frequentada, cheio de transeuntes entre o comércio e o metrô, enquanto o espaço do centro cultural era relativamente pouco utilizado, passando a maior parte do tempo despercebido. Assim, o artista propôs a extensão da tubulação elétrica do jardim do Centro Cultural até a calçada, disponibilizando energia elétrica $24 \mathrm{~h}$ gratuitamente. Esta intervenção transformou o uso cotidiano do espaço ao redor, tornando-se quase uma entidade material, na medida em que os taxistas trouxeram para seu ponto uma televisão e que o senhor que serviu de inspiração do trabalho pôde enfim demonstrar a qualidade do som dos discos que ele ali vendia. $\mathrm{O}$ trabalho, portanto, buscou a conexão entre espaços, operando com uma lógica característica da arte contemporânea, que, conforme as palavras do crítico Alberto Tassinari: “[...] não transcende espacialmente o mundo e o espaço em comum, mas antes nasce deles e retorna à vida cotidiana acrescentando-lhe novos sentidos" (TASSINARI, 2001: 88). Dessa maneira, a intervenção tornou-se uma espécie de vetor de encontros no lugar e com o lugar.

$\mathrm{O}$ arquiteto mineiro Carlos Teixeira também partiu da transformação do uso do espaço para realizar suas obras Amnésias Topográficas I (Belo Horizonte, 2001. Cenário feito com tapumes e madeira para a peça Invento para Leonardo, realizado em baixo de um edifício) e Amnésias Topográficas II (Belo Horizonte, 2004. Cenário feito com tapu- 
mes, madeira e capim para a peça Nômades, realizado em baixo de dois edifícios contíguos). Nelas, o arquiteto, em parceria com o grupo de teatro de rua Armatrux, concebeu um novo significado ao espaço labiríntico de pilotis gerado pela implantação de edifícios residenciais em um terreno em declive no bairro Buritis. Ambas as intervenções convertiam a área de difícil acesso, ignorada pelos condôminos e com aspecto de depósito de entulho, em um espaço ativado e revelado como cenário dos espetáculos Invento para Leonardo (2001) e Nômades (2004), escritos por Paulo Azevedo, com dramaturgia concebida especificamente para esses lugares.

No espetáculo Invento para Leonardo, as pessoas não puderam entrar e vivenciar o espaço interno dos pilotis, pois ele era limitado apenas um edifício - e o grupo de teatro preferiu usar a arquibancada interna apenas como parte do cenário, uma vez que sua capacidade de público (50 pessoas) era bem menor do que a arquibancada externa (200 pessoas) que ficava num lote vago em frente aos pilotis (TEIXEIRA, 2014: 4). Os vizinhos debaixo do edifício, principalmente aqueles que faziam divisa com o lote vago que dava acesso aos pilotis, estavam muitos satisfeitos com a intervenção, pois foram beneficiados visualmente pelo espetáculo (TEIXEIRA, 2014: 7). Eles testemunharam a retirada de várias caçambas de entulho antes de se começar a produção do cenário. Dessa maneira, foram simpáticos à ideia e assistiram aos espetáculos de suas varandas, que, voltadas para o lote vago, eram como que balcões da plateia. 
Observando esse mesmo terreno, notou-se que os prédios enfileirados têm divisões e muros no nível da rua, com separação de propriedades, lotes e condomínio, mas que, por baixo, não há divisão alguma, apenas um único vazio contínuo. Amnésias Topográficas II explorava esse vazio de prédios contíguos, que a princípio envolvia cinco edifícios, de maneira a construir um "percurso mais ou menos linear por dentro desse espaço meio cavernoso" (TEIXEIRA, 2014: 3). Porém, o terceiro prédio não quis ceder o espaço e o projeto ficou limitado somente a dois edifícios. Adaptado, ele se transformou de linha para espiral, um percurso espiralado com um paisagismo de fibras de coco, caixas de feira e capins, e com algumas salas, mini palcos pedidos pelo grupo Armatrux, aonde aconteciam algumas cenas (TEIXEIRA, 2014: 3). A partir, disso a peça Nômades foi concebida, quase como esse próprio percurso de exploração do espaço, no qual o público subia quatro andares.

Neste percurso, Amnésias Topográficas II assemelhava-se a estratégias da arte na contemporaneidade explicitada por Mammì, em que o trabalho "se dissolve na multiplicação das modalidades de percepção" (MAMMÌ, 2012: 87). Ainda segundo esse autor, o valor da obra "já não está mais nela, mas nas operações visuais que cumprimos a partir dela”. (MAMMÌ, 2012: 87). Assim também pode ser percebida a intervenção, que permitia ao público visitar todos os recantos das palafitas, unindo palco e plateia, atores e público, e experimentar arquitetura, paisagismo e recuperação ambiental em uma cenografia dada no espaço antes desconexo. Teixeira comenta que o espetáculo funcionou como um urba- 
nismo efêmero, apontando para desequilíbrios urbanos e invertendo a lógica da privatização de um país em que as cidades são cada vez menos públicas - vistas como obstáculos, ou até mesmo como inimigas.

Outro trabalho, Espaços Públicos Invisíveis (Nova York, 2008, não realizado. Estrutura parasita nos vitrais da estação de trem e metrô Central Station de Nova York que seria utilizada como cenário de uma peça da Cia. Suspensa de Dança), seria também um processo colaborativo, entre o arquiteto e Cia. Suspensa de Dança. A obra buscaria lugares que poderiam ter algum potencial de ocupação pública, mas que não eram utilizados dessa maneira, "espaços que tenham usos pré-definidos e que possam ser questionados por meio de um evento [...] conflitante com as expectativas de uso desses espaços" (TEIXEIRA, 2010: 258). Vários foram elencados como potenciais e uma intervenção na estação de trem e metrô Central Station foi preliminarmente desenvolvida e representada graficamente para o concurso. Assemelhando-se à colocação de Lorenzo Mammì, "se é o espaço quem detém o valor, o objetivo do artista será, antes de tudo, sua ocupação" (MAMMÌ, 2012: 102). Nesse sentido, apesar de não realizada, a proposta desperta a reflexão e investigação sobre a ocupação dos espaços públicos mais emblemáticos da cidade.

Destacaram-se acima algumas características dos trabalhos em questão. A análise dessas intervenções vale-se de três livros referenciais teóricos, que procuram identificar e interpretar as principais características da produção artística contemporânea, bem como compará-las às da arte moderna. São eles: Estética Relacional, de Nicolas Bourriaud; $O$ 
espaço moderno, de Alberto Tassinari; e $O$ que resta, de Lorenzo Mammì. Em Estética Relacional, Bourriaund discute a tendência política das obras contemporâneas em investir e problematizar a esfera das relações humanas, afirmando a importância do contexto social para a compreensão de noções interativas. Já Tassinari traz para seu ensaio a potencialidade da arte em inventar modos de renovar a vida social trazendo novas configurações de um assunto e espaço previamente conhecido. Ele define um espaço moderno como um espaço em obra, que pode ser visto como ainda se fazendo. Para Mammì, não há como desvincular obra e espaço contemporâneos, pois aquela tem uma articulação única e característica com este, despertando um sentido que o próprio espaço já carrega em potencial. Além desses livros, a tese de doutorado Dentro do nevoeiro: Diálogos cruzados entre arte e arquitetura contemporânea, em que Guilherme Wisnik relaciona poéticas artísticas e arquitetônicas na contemporaneidade, também foi de suma importância para o embasamento desta pesquisa.

Tendo em vista estes teóricos, pode-se concluir que o modo como o espaço cotidiano e "banal" é tratado pelos trabalhos apresentados herda características do modernismo, pop art e principalmente do foundobject, estratégia mais conhecida pela série de ready-mades de Marcel Duchamp. O found-object é inquietante pois trata-se de um mero objeto deslocado de seu ambiente para um espaço expositivo, de modo que as operações pelas quais o artista mostra sua obra sobrepõem-se ao objeto em si. Numa mesma vertente, os trabalhos aqui em questão atribuem valor estético a espaços cotidianos ao invés de um objeto, também de 
maneira estranha e inesperada, porém mais discreta e democrática, uma vez que, em meio à dinâmica da cidade, podem atingir qualquer transeunte. Nesse sentido, aproximam-se de experiências e discussões trabalhadas pelo artista brasileiro Hélio Oiticica, que declarou que o "museu é o mundo", isto é, a experiência cotidiana, e de artistas como Richard Serra, Robert Smithson e Gordon Matta-Clark, que trabalham o conceito de site-specificity, atribuindo valor aos espaços e às suas especificidades. Dessa forma, o significado dos trabalhos não está "mais ligado à sua autonomia, e sim à sua dimensão contextual" (MANO, 2003: 8), quer dizer, os trabalhos não funcionam mais como objetos independentes do espaço onde eles aparecem ou acontecem, mas dependem justamente do contexto em que ocorrem e das relações físicas, espaciais, sociais e simbólicas que propiciam.

Os trabalhos de Ganz, Mano e Teixeira referenciam muitos pensamentos das décadas 1960/70 quando deslocam o significado de espaços desconexos conferindo-lhes uma qualidade nova. Como coloca Laymert Garcia dos Santos: "o lugar é o mesmo de sempre e, no entanto, outro" (SANTOS, 2002). A quebra da rotina urbana que proporcionam desregula valores em planos diversos propondo sentidos conflitantes, e, assim, "ressignifica o espaço e o sujeito, bem como a cidade e a cidadania" (SANTOS, 2002). Dessa maneira, os trabalhos aqui em questão podem ser compreendidos a partir da perspectiva fornecida por Nicolas Bourriaud na medida em que "não perseguem a meta de formar realidades imaginárias ou utópicas, mas procuram construir modos de 
existência ou modelos de ação dentro da realidade existente" (BOURRIAUD, 2009: 18).

O caráter efêmero comum aos trabalhos analisadas permite, com recursos relativamente escassos, rapidamente ativar espaços e discussões públicas. Por exemplo, alguns anos depois de Amnésias Topográficas II, houve uma revisão do plano diretor de Belo Horizonte na qual se discutiu como impedir que novos pilares como aqueles abordados por Teixeira fossem construídos, o que demonstra o grande potencial de reverberação dessas ações (TEIXEIRA, 2014: 7, 8). A ação de Teixeira foi provavelmente um dos fatores que desencadeou a discussão sobre a relação entre os edifícios, a geografia e a cidade ao entorno, de modo a se repensar espaços residuais como aqueles ocupados por ambas Amnésias Topográficas I e Amnésias Topográficas II. Assim, as repercussões destas ações foram muito positivas. Entretanto, a solução adotada pelo novo plano para evitar a criação de novos espaços como aqueles foi simplesmente fechá-los com tijolos, ou seja, afirmar sua negação, sem um pensamento crítico e criativo de fato sobre o assunto.

Com a qualidade de trabalhar o imaginário, esses trabalhos partem de uma leitura urbana para subverter a lógica dos espaços em que se dão, entendendo-os como dimensões abertas à reconstrução de seus sentidos e permitindo, assim, experiências e vivências antes bloqueadas e impensáveis. Como coloca Sansão Fontes, em contrapartida às intervenções caras, permanentes e de grande escala, os projetos temporários se dão no âmbito do pequeno, das relações sociais, provocando participação, interação e subversão de situações reais específicas (SANSÃO 
FONTES, 2011: 30). Já as intervenções permanentes podem até provocar o mesmo num primeiro momento, porém, com o tempo, são incorporadas às próprias dinâmicas usuais, perdendo sua força como deslocamento.

Assim, as evidentes reflexões espaciais desenvolvidas pelos trabalhos aqui analisados e as relações entre indivíduo e espaço colocadas nos fazem questionar os limites entre arte e arquitetura. Enfim, independente do que pode ser discutido nesse sentido, a potência dos trabalhos está na premissa da execução, apropriação e confronto de ações em espaços urbanos e cotidianos, de forma prática e efetiva. Como escreve Nicolas Bourriaud, "parece mais urgente inventar relações possíveis com os vizinhos de hoje do que entoar loas ao amanhã" (BOURRIAUD, 2009: 62). Neste sentido, as discussões trazidas por estas obras se mostram atuais e relevantes para questionar os desequilíbrios urbanos e o quadro de privatização dos espaços da cidade, bem como pensar uma construção e desenvolvimento destas, contribuindo, assim, para a reflexão e a prática da arte, arquitetura e urbanismo contemporânea.

\section{Referências Bibliográficas}

AUGÉ, Marc. Não lugares: Introdução a uma antropologia da supermodernidade. Campinas: Papirus, 2012.

BATISTA, Helmut e MANO, Rubens. "Rubens Mano e Helmut Batista (entrevista)", Jornal Capacete n ${ }^{\circ}$ 4, Capacete Projects, Rio de Janeiro, julho de 2002.

BISHOP, Claire. “Antagonismo e Estética Relacional”, Revista Tatuí, no 12 , janeiro de 2012. 
BOHNS, Neiva, "Arte na cidade: do lado de fora, no meio de tudo", Revista Panorama Crítico (online), n.11, s.d. Disponível em <http://www.panoramacritico.com/revista/index.php/ensaios/8-ensaios> Acesso em 20 jul. 2014.

BOURRIAUD, Nicolas. Estética relacional. São Paulo: Martins Fontes, 2009.

CHIARELLI, Tadeu. "A cidade não mais como obstáculo: a produção de Rubens Mano”, IN: MANO, Rubens. Rubens Mano. São Paulo: Casa Triângulo, 2000.

GANZ, Louise. "Lotes vagos: Ação Coletiva de Ocupação Urbana Experimental", Revista Ars, v.6, n¹1, Revista do Departamento de Arte Plásticas da ECA/USP, São Paulo, 2008. Disponível em $<$ http://www.scielo.br/scielo.php?script=sci_arttext\&pid=S1678$53202008000100013 \& \operatorname{lng}=$ en \&nrm=iso> Acesso em 20 jul. 2014.

. Louise Ganz: depoimento [jan. 2014]. Entrevistador: Julia Pinto. Belo Horizonte, 2014. Transcrição da entrevista gravada. Entrevista concedida para o trabalho de Iniciação Científica Espaços Invisíveis: Arte e Arquitetura na Cidade Contemporânea, realizado junto ao Programa de Iniciação Científica da Escola da Cidade.

GANZ, Louise e SILVA, Breno. Lotes Vagos: ocupações experimentais. Belo Horizonte: Instituto Cidades Criativas, 2009.

- página eletrônica do projeto Lotes Vagos: EXPANSÕES ação coletiva de ocupação urbana experimental. Disponível em <http://lotevago.blogspot.com.br/> Acesso em 20 jul. 2014.

HARVEY, David. “A liberdade da Cidade”, Revista Urbânia, no 3. São Paulo: Editora Pressa, 2008.

KOOLHAAS, Rem e MAU, Bruce. $S M L X L$. Nova York: Monacelli Press, 1995. 
MAMMÌ, Lorenzo. “À margem”, Revista Ars, v. 2, no 3, Revista do Departamento de Arte Plásticas da ECA/USP, São Paulo, 2004.

. O que resta - arte e crítica de arte. São Paulo: Companhia das Letras, 2012.

MANO, Rubens. Intervalo transitivo. (Dissertação de Mestrado). São Paulo: ECA/USP, 2003.

. "A condição do lugar no site*”, Revista Ars, v. 4, no 7, Revista do Departamento de Arte Plásticas da ECA/USP, São Paulo, 2006.

. O espaço enquanto imagem projetada (vídeo 57:24min). Palestra realizada na Escola da Cidade. Disponível em $<$ http://escoladacidade.org/bau/rubens-mano-o-espaco-enquantoimagem-projetada/> Acesso em 03 out. 2013.

. Rubens Mano: depoimento [jan. 2014]. Entrevistador: Julia Pinto. São Paulo, 2014. Transcrição da entrevista gravada. Entrevista concedida para o trabalho de Iniciação Científica Espaços Invisíveis: Arte e Arquitetura na Cidade Contemporânea, realizado junto ao Programa de Iniciação Científica da Escola da Cidade.

. "Um lugar dentro do lugar", Revista Urbânia, no 3. São Paulo: Editora Pressa, 2008.

NAVARRO, Janaína. "Let's Play" (texto crítico), folder da exposição Let's Play. São Paulo: Galeria Casa Triângulo, 2008. Disponível em <http://www.galeriamillan.com.br/pt-BR/texto-critico/31> Acesso em 20 jul. 2014.

O'DOHERTY, Brian. Inside the white cube: The Ideology of the Gallery Space. San Francisco: The Lapis Press, 1986.

PALlAMIN, Vera. Arte urbana: São Paulo - Região Central (19451998) Obras de caráter temporário e permanente. São Paulo: Fapesp, 2000. 
PEIXOTO, Nelson Brissac. Intervenções Urbanas: Arte/Cidade. São Paulo: Editora SENAC São Paulo, 2002.

RIVITTI, Thaís. "Uma obra para museu”, Revista Ars, no 13, Revista do Departamento de Arte Plásticas da ECA/USP, São Paulo, 2010.

SANSÃO FONTES, Adriana. Intervenções temporárias, marcas permanentes. A amabilidade nos espaços coletivos de nossas cidades. (Tese de Doutorado). Rio de Janeiro: PROURB-FAU/UFRJ, 2011.

. Intervenções temporárias no Rio de Janeiro contemporâneo: novas formas de usar a cidade. Disponível em <http://www.vitruvius.com.br/revistas/read/arquitextos/13.154/4678> Acesso em 20 jul. 2014.

SANTOS, Laymert Garcia dos. "Uma arte do espaço e de sua produção" (texto crítico). São Paulo: Casa Triângulo, 2002. Disponível em <http://www.galeriamillan.com.br/pt-BR/texto-critico/13> Acesso em 20 jul. 2014.

. Do espaço moderno ao espírito do lugar, in: Futuro do Pretérito (folder), Museu Nacional, Brasília, 2010.

SOLÀ-MORALES, Ignasi. Terrain-Vague. $1^{\circ}$ mar. 2012 Disponível em <http://www.archdaily.com.br/br/01-35561/terrain-vague-slash-ignaside-sola-morales> Acesso em 20 jul. 2014.

TASSINARI, Alberto. O espaço moderno. São Paulo: Cosac Naify Edições, 2001.

TEIXEIRA, Carlos M. Entre. Belo Horizonte: Instituto Cidades Criativas, 2010.

- Carlos Teixeira: depoimento [jan. 2014]. Entrevistador: Julia Pinto. Belo Horizonte, 2014. Transcrição da entrevista gravada. Entrevista concedida para o trabalho de Iniciação Científica Espaços Invisíveis: Arte e Arquitetura na Cidade Contemporânea, realizado junto ao Programa de Iniciação Científica da Escola da Cidade. 
Cadernos de Clio, Curitiba, v. 6, nº. 2, 2015

WISNIK, Guilherme. Dentro do nevoeiro: Diálogos cruzados entre arte $e$ arquitetura contemporânea. (Tese de Doutorado). São Paulo: FAUUSP, 2012.

Recebido em: 13/06/2015 Aceito em: 22/11/2015 